\title{
Frequency evaluation of different extraction protocols in orthodontic treatment during 35 years
}

Guilherme Janson*, Fábio Rogério Torres Maria and Roberto Bombonatti

\begin{abstract}
Background: Studies that show frequencies of different orthodontic treatment protocols can be used as valuable parameters in the interpretation of treatment tendency with time. The purpose of this retrospective study was to evaluate all orthodontic treatment planning conducted at the Orthodontic Department at Bauru Dental School, University of São Paulo, Brazil, since 1973, in order to investigate extraction and non-extraction protocol frequencies selected at each considered period.

Methods: The sample comprised 3,413 records of treated patients and was evaluated according to the protocol choice, divided into 10 groups: Protocol 0 (non-extraction); Protocol 1 (four first premolar extractions); Protocol 2 (two first maxillary and two second mandibular premolars); Protocol 3 (two maxillary premolar extractions); Protocol 4 (four second premolars); Protocol 5 (asymmetric premolar extractions); Protocol 6 (incisor or canine extractions); Protocol 7 (first or second molar extractions); Protocol 8 (atypical extractions) and Protocol 9 (agenesis and previously missing permanent teeth). These protocols were evaluated in seven 5-year intervals: Interval 1 (1973 to 1977); Interval 2 (1978 to 1982); Interval 3 (1983 to 1987); Interval 4 (1988 to 1992); Interval 5 (1993 to 1997); Interval 6 (1998 to 2002); Interval 7 (2003 to 2007). The frequency of each protocol was compared between the seven intervals, using the proportion test $(P<0.05)$.

Results: The results showed that 10 protocol frequencies were significantly different among the 7 time intervals. Conclusions: The non-extraction protocol frequency increased gradually with consequent reduction of extraction treatments. The four premolar extraction protocol frequency decreased gradually while the two maxillary premolar extraction protocol has maintained the same frequency of indications throughout time.
\end{abstract}

Keywords: Orthodontic treatment; Frequency of treatment protocols; Extraction vs non-extraction

\section{Background}

The decision to extract teeth or not and the number of teeth to be extracted can influence the final result of orthodontic treatment, including esthetics, occlusion, satisfaction of patients and their families, as well as the treatment time $[1,2]$. For many years the extraction decision has instigated much discussion and controversies, often linked to personal preferences than scientific criteria [3]. In the last decades, Orthodontics has experienced conceptual and technological changes influenced by dominant trends in each time. Extraction orthodontic treatment, as an actual and accessible alternative therapy also seems to be susceptible to moments of transition.

Retrospective studies [3-8] of extraction frequencies in orthodontic treatments are quite scarce and usually reflect the reality of North America or Europe. In this way, it would be interesting to verify if the extraction frequencies in other parts of the world are different from these places. Therefore, the purpose of this retrospective study was to evaluate the frequency of the different treatment protocols at the Orthodontic Department of Bauru Dental School, University of São Paulo, Brazil, during the last 35 years.

\footnotetext{
* Correspondence: jansong@travelnet.com.br

Department of Orthodontics, Bauru Dental School, University of São Paulo,

Alameda Octávio Pinheiro Brisolla 9-75, Bauru, SP 17012-901, Brazil
} 


\section{Methods}

The data was retrospectively obtained from 3,745 consecutively treated patients from the files of the Orthodontic Department at Bauru Dental School, University of São Paulo, from 1973 to 2007. Patient files (records, extraoral, and intraoral photographs, radiographs and study models) were sequentially evaluated and 332 (8.86\%) were excluded, resulting in 3,413 cases in the sample. Exclusion criteria were patient transfer or treatment drop out, preventive and orthopedic treatment without following orthodontic treatment with fixed appliances and cases without complete records.

The sample consisted of 1,475 males (43.21\%) and 1,938 females $(56.79 \%)$ treated with an initial mean age of 13.76 years ( $\mathrm{SD} \pm 3.65$; range 5.20 to 49.00 years), divided according to the treatment protocol: Protocol 0 (nonextraction); Protocol 1 (four first premolar extractions); Protocol 2 (two maxillary first and two mandibular second premolar or a variation to three first premolar and one mandibular second premolar extractions); Protocol 3 (two maxillary premolar extractions); Protocol 4 (four second premolar or a variation to three second premolar and one mandibular first premolar extractions); Protocol 5 (asymmetric extractions - three premolars or only one premolar); Protocol 6 (incisor or canine extractions); Protocol 7 (first or second molar extractions); Protocol 8 (atypical extractions) and Protocol 9 (patients with agenesis or previously missing permanent teeth). The frequency of these protocols were evaluated in seven 5-year intervals similar to Profitt [8]: Interval 1 (1973 to 1977); Interval 2 (1978 to 1982); Interval 3 (1983 to 1987); Interval 4 (1988 to 1992); Interval 5 (1993 to 1997); Interval 6 (1998 to 2002); and Interval 7 (2003 to 2007). The frequency of each protocol was compared among the seven intervals in order to identify some predominant trends at each tested period. Onephase and two-phase treatments and re-planned cases that included extractions in the new planning were also quantified. After 3 weeks, 30 patients were randomly selected, and their treatment protocols were re-evaluated by the same examiner to verify the intraexaminer error.

The study protocol was approved by the Ethics Committee on Human Research of Bauru Dental School, University of São Paulo.

\section{Statistical analysis}

The frequencies of each protocol were compared among the intervals with the proportion test [9]. Results were considered significant at $P<0.05$. These analyses were performed with Statistica software (Statistica for Windows version 7.0, Statsoft, Tulsa, Okla.).

\section{Results}

All 30 re-evaluated patient records presented complete agreement with the first observation, confirming the high reproducibility of the methodology. Figure 1 shows the frequency increase of non-extraction treatments and the reduction in the number of extraction treatments and four premolar extraction protocol in all evaluated intervals. Some protocol frequencies were significantly different among the seven intervals (Table 1). The twophase treatments and the occurrence of re-planned case frequencies comparison are presented in Table 2.

\section{Discussion}

Because the sample consisted of all treated patients in the Orthodontic Department at Bauru Dental School, from 1973 to 2007, it would not be necessary to apply inferential statistical tests. Even though, to provide more mathematical precision, the Proportion Test was used to evaluate whether there was any significant difference in the treatment protocol frequencies between each time interval. This type of frequency distribution test is strongly influenced by the number of events observed. This explains why, in Table 1, the frequency of protocol

\section{FREQUENCY (\%)}

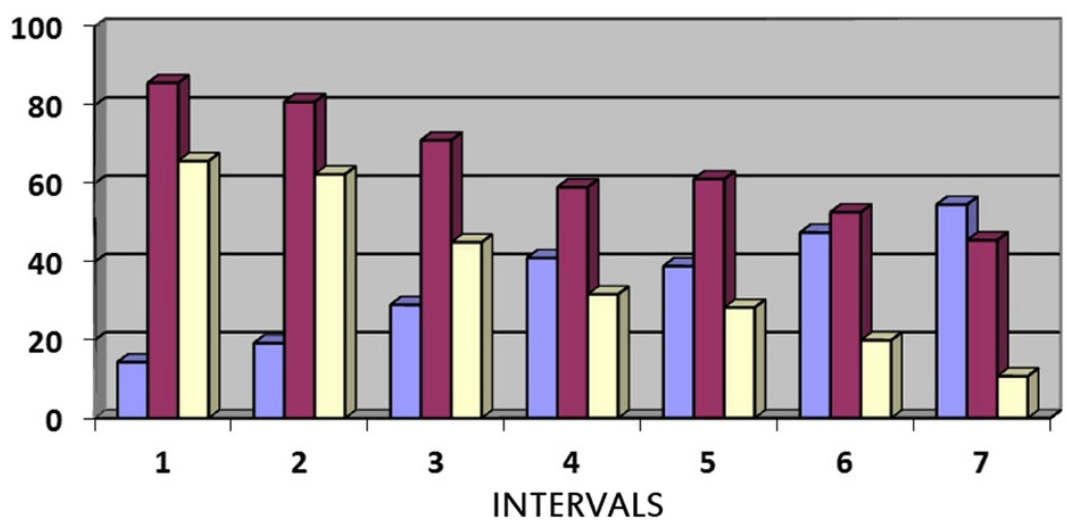

$\square$ Non-extraction
$\square$ Extraction
$\square 4$ Premolar Extraction

Figure 1 Frequency of extraction and non-extraction treatment and premolar extraction protocol in all evaluated intervals. 
Table 1 Frequency of 10 treatment protocols in all evaluated intervals (proportion test)

\begin{tabular}{|c|c|c|c|c|c|c|c|c|c|c|c|c|c|c|c|c|c|c|c|c|c|c|}
\hline \multirow{4}{*}{ Interval } & \multicolumn{20}{|c|}{ Protocol } & \multicolumn{2}{|c|}{ Total } \\
\hline & \multicolumn{2}{|c|}{0} & \multicolumn{2}{|c|}{1} & \multicolumn{2}{|c|}{2} & \multicolumn{2}{|c|}{3} & \multicolumn{2}{|c|}{4} & \multicolumn{2}{|c|}{5} & \multicolumn{2}{|c|}{6} & \multicolumn{2}{|c|}{7} & \multicolumn{2}{|c|}{8} & \multicolumn{2}{|c|}{9} & \multirow{3}{*}{$N$} & \multirow{3}{*}{$\%$} \\
\hline & \multicolumn{2}{|c|}{$\begin{array}{c}\text { Non- } \\
\text { extraction }\end{array}$} & \multicolumn{2}{|c|}{$\begin{array}{l}\text { Four first } \\
\text { premolar } \\
\text { extractions }\end{array}$} & \multicolumn{2}{|c|}{$\begin{array}{l}\text { Two maxillary first } \\
\text { and two } \\
\text { mandibular second } \\
\text { premolar } \\
\text { extractions }\end{array}$} & \multicolumn{2}{|c|}{$\begin{array}{l}\text { Two maxillary } \\
\text { premolar } \\
\text { extractions }\end{array}$} & \multicolumn{2}{|c|}{$\begin{array}{l}\text { Four second } \\
\text { premolar } \\
\text { extractions }\end{array}$} & \multicolumn{2}{|c|}{$\begin{array}{l}\text { Asymmetric } \\
\text { extractions - three } \\
\text { premolars or only } \\
\text { one premolar }\end{array}$} & \multicolumn{2}{|c|}{$\begin{array}{l}\text { Incisor or } \\
\text { canine } \\
\text { extractions }\end{array}$} & \multicolumn{2}{|c|}{$\begin{array}{c}\text { First or } \\
\text { second molar } \\
\text { extractions }\end{array}$} & \multicolumn{2}{|c|}{$\begin{array}{l}\text { Atypical } \\
\text { extractions }\end{array}$} & \multicolumn{2}{|c|}{$\begin{array}{l}\text { Agenesis or } \\
\text { previously } \\
\text { missing } \\
\text { permanent } \\
\text { teeth }\end{array}$} & & \\
\hline & $N$ & $\%$ & $N$ & $\%$ & $N$ & $\%$ & $N$ & $\%$ & $N$ & $\%$ & $N$ & $\%$ & $N$ & $\%$ & $N$ & $\%$ & $N$ & $\%$ & $N$ & $\%$ & & \\
\hline $\begin{array}{l}1 \\
\text { (1973 to } 1977)\end{array}$ & 15 & $\begin{array}{c}A \\
14.29\end{array}$ & 57 & $\begin{array}{c}A \\
54.29\end{array}$ & 11 & $\begin{array}{l}A B C \\
10.48\end{array}$ & 6 & $\begin{array}{c}\mathrm{BC} \\
5.71\end{array}$ & 1 & $\begin{array}{c}\mathrm{BC} \\
0.95\end{array}$ & 1 & $\begin{array}{l}A B C \\
0.95\end{array}$ & 0 & 0 & 0 & 0 & 2 & 1.90 & 12 & 11.43 & 105 & 3.08 \\
\hline $\begin{array}{l}2 \\
\text { (1978 to } 1982 \text { ) }\end{array}$ & 28 & $\begin{array}{c}A B \\
19.18\end{array}$ & 84 & $\begin{array}{c}\text { A } \\
57.53\end{array}$ & 5 & $\begin{array}{l}C D \\
3.42\end{array}$ & 5 & $\begin{array}{c}A B \\
3.42\end{array}$ & 2 & $\begin{array}{c}B C \\
1.37\end{array}$ & 1 & $\begin{array}{l}A B \\
0.68\end{array}$ & 0 & 0 & 0 & 0 & 2 & 1.37 & 19 & 13.01 & 146 & 4.28 \\
\hline $\begin{array}{l}3 \\
\text { (1983 to } 1987)\end{array}$ & 91 & $\begin{array}{c}\text { B } \\
28.98\end{array}$ & 90 & $\begin{array}{c}B \\
28.66\end{array}$ & 40 & $\begin{array}{c}\text { A } \\
12.74\end{array}$ & 34 & $\begin{array}{c}B C \\
10.83\end{array}$ & 11 & $\begin{array}{l}C D \\
3.50\end{array}$ & 4 & $\begin{array}{c}A \\
1.27\end{array}$ & 1 & 0.32 & 3 & 0.96 & 14 & 4.46 & 26 & 8.28 & 314 & 9.20 \\
\hline $\begin{array}{l}4 \\
\text { (1988 to } 1992 \text { ) }\end{array}$ & 273 & $\begin{array}{c}C D \\
40.99\end{array}$ & 170 & $\begin{array}{c}\text { B } \\
25.53\end{array}$ & 34 & $\begin{array}{c}B C \\
5.11\end{array}$ & 62 & $\begin{array}{l}B C \\
9.31\end{array}$ & 7 & $\begin{array}{c}B C \\
1.05\end{array}$ & 13 & $\begin{array}{c}\text { A } \\
1.95\end{array}$ & 2 & 0.30 & 7 & 1.05 & 23 & 3.45 & 75 & 11.26 & 666 & 19.51 \\
\hline $\begin{array}{l}5 \\
\text { (1993 to 1997) }\end{array}$ & 491 & $\begin{array}{c}C \\
38.91\end{array}$ & 281 & $\begin{array}{c}\text { B } \\
22.27\end{array}$ & 63 & $\begin{array}{c}B C \\
4.99\end{array}$ & 137 & $\begin{array}{c}C D \\
10.8\end{array}$ & 13 & $\begin{array}{c}B C \\
1.03\end{array}$ & 61 & $\begin{array}{c}B C \\
4.83\end{array}$ & 6 & 0.48 & 10 & 0.79 & 61 & 4.83 & 139 & 11.01 & 1262 & 36.98 \\
\hline $\begin{array}{l}6 \\
\text { (1998 to 2002) }\end{array}$ & 290 & $\begin{array}{c}\mathrm{DE} \\
47.39\end{array}$ & 95 & $\begin{array}{c}C \\
15.52\end{array}$ & 25 & $\begin{array}{l}B C D \\
4.08\end{array}$ & 67 & $\begin{array}{c}C D \\
10.95\end{array}$ & 2 & $\begin{array}{c}A B \\
0.33\end{array}$ & 44 & $\begin{array}{c}C \\
7.19\end{array}$ & 1 & 0.16 & 6 & 0.98 & 19 & 3.10 & 63 & 10.29 & 612 & 17.93 \\
\hline $\begin{array}{l}7 \\
\text { (2003 to 2007) }\end{array}$ & 168 & $\begin{array}{c}E \\
54.55\end{array}$ & 23 & $\begin{array}{c}D \\
7.47\end{array}$ & 4 & $\begin{array}{c}\mathrm{D} \\
1.30\end{array}$ & 23 & $\begin{array}{c}B C \\
7.47\end{array}$ & 6 & $\begin{array}{c}B C \\
1.95\end{array}$ & 21 & $\begin{array}{c}C \\
6.82\end{array}$ & 0 & 0 & 2 & 0.65 & 10 & 3.25 & 51 & 16.56 & 308 & 9.02 \\
\hline Total & 1,356 & 39.73 & 800 & 23.43 & 182 & 5.3 & 334 & 9.78 & 42 & 1.23 & 145 & 4.24 & 10 & 0.29 & 28 & 0.82 & 131 & 3.83 & 385 & 11.28 & 3,413 & 100 \\
\hline$\chi$ & 113 & 305 & & 2.758 & & & & 668 & & 443 & & & & 40 & & 97 & & 540 & & 522 & & \\
\hline$P$ & 0.00 & $00^{*}$ & & $000^{*}$ & & & & $335^{*}$ & & $34^{*}$ & & & & 518 & & 215 & & 948 & & 512 & & \\
\hline
\end{tabular}

Different letters represent statistically significant differences in same protocol. * ${ }^{*}$ tatistically significant at $P<0.05$. 
Table 2 Frequency of one-phase and two-phase treatments and re-planned cases in all evaluated intervals (proportion test)

\begin{tabular}{|c|c|c|c|c|c|c|c|c|c|}
\hline \multirow{2}{*}{ Interval } & \multirow{2}{*}{$N$} & \multicolumn{2}{|c|}{ One-phase } & \multicolumn{2}{|c|}{ Two-phase } & \multicolumn{2}{|c|}{ Not replanned } & \multicolumn{2}{|c|}{ Re-planned } \\
\hline & & $N$ & $\%$ & $N$ & $\%$ & $N$ & $\%$ & $N$ & $\%$ \\
\hline $\begin{array}{l}1 \\
\text { (1973 to } 1977)\end{array}$ & 105 & 104 & 99.05 & 1 & $0.95^{\mathrm{A}}$ & 104 & 99.05 & 1 & $0.95^{B C}$ \\
\hline $\begin{array}{l}2 \\
\text { (1978 to } 1982 \text { ) }\end{array}$ & 146 & 145 & 99.32 & 1 & $0.68^{\mathrm{A}}$ & 143 & 97.94 & 3 & $2.06^{B C}$ \\
\hline $\begin{array}{l}3 \\
\text { (1983 to } 1987 \text { ) }\end{array}$ & 314 & 309 & 98.73 & 5 & $1.27^{\mathrm{A}}$ & 305 & 97.13 & 9 & $2.87^{B C}$ \\
\hline $\begin{array}{l}4 \\
\text { (1988 to } 1992 \text { ) }\end{array}$ & 666 & 636 & 98.05 & 30 & $1.95^{\mathrm{AB}}$ & 653 & 98.05 & 13 & $1.95^{B C}$ \\
\hline $\begin{array}{l}5 \\
\text { (1993 to } 1997 \text { ) }\end{array}$ & 1262 & 1172 & 95.17 & 90 & $4.83^{B C}$ & 1226 & 97.15 & 36 & $2.85^{B C}$ \\
\hline $\begin{array}{l}6 \\
\text { (1998 to } 2002 \text { ) }\end{array}$ & 612 & 521 & 92.81 & 91 & $7.19^{\mathrm{D}}$ & 587 & 95.91 & 25 & $4.09^{\mathrm{AB}}$ \\
\hline $\begin{array}{l}7 \\
\text { (2003 to 2007) }\end{array}$ & 308 & 296 & 93.18 & 12 & $6.82^{\mathrm{AB}}$ & 306 & 99.35 & 2 & $0.65^{C D}$ \\
\hline Total & 3,413 & 3,183 & 93.26 & 230 & 6.74 & 3324 & 97.39 & 89 & 2.61 \\
\hline & & & & & & & & & \\
\hline & & & & & & & & & \\
\hline
\end{tabular}

Different letters in two-phase treatment or in re-planned cases represent statistically significant differences. *Statistically significant at $P<0.05$.

5 in interval $7(6.82 \%)$ is statistically different from interval $3(1.27 \%)$, but not different from interval 1 (0.95\%).

In this study, the treatment protocols with (Protocols 1 to 9) and without extractions (Protocol 0) showed great statistically significant variation among the considered intervals (Figure 1 and Table 1). In the first interval, 1973 to $1977,85.71 \%$ of cases were treated with some type of extraction protocol, demonstrating the influence of extraction dogmas at that time $[10,11]$. This tendency decreased, similar to other studies [6-8], until it reaches a frequency of $45.45 \%$ of cases with extractions in the last interval 2003 to 2007 . These findings clearly demonstrate the great influence of extraction concepts on the percentage of cases treated with extractions in the 1960s and 1970s [10-13]. Since then, there has been a decrease of extraction treatment consequent to studies which showed relapses even in these cases [14,15], the possibility of protruding the mandibular incisors in some situations $[16,17]$, the belief that there could be a relationship between extractions and temporomandibular disorders $[18,19]$, and the possibility of treatments with interproximal stripping [20,21]. Technical changes also may have also influenced this decline, such as an increase in orthopedic appliances usage [22], maxillary expanders [23], as well as treatment in two phases [24,25].

The choice for four first premolars was for a long time the classic extraction protocol [10,26]. However, more recently, there are reports about treatment difficulty [27], greater treatment time [28], and risks of root resorption and periodontal problems [29], especially in adult patients. Investigations indicate that dental extractions tend to prolong treatment time, in general [30,31].

In this study, the frequency of treatments with four first premolar extractions (Protocol 1) decreased significantly, corroborating the findings of other studies [3,6-8] (Table 1). The frequency of two maxillary first premolar and two mandibular second premolar extraction protocol (Protocol 2) also demonstrated statistically significant differences among the evaluated intervals (Table 1 ). This reduction, also observed by others researchers [6-8], appears to have been influenced by the same historical reasons discussed for the four first premolar extractions protocol.

The two maxillary premolar extraction protocol (Protocol 3) showed a relatively stable frequency around 10\% in most of the evaluated periods (Table 1). This fact can be interpreted as an increase in preference of this specific protocol due to drastic reduction of extraction treatment between 1973 and 2007 (Figure 1). In other investigations, frequencies ranged from 5\% [5] to 22\% [6]. Maxillary premolar extractions seem to be very useful in Class II malocclusion orthodontic treatment $[18,28,32,33]$. This treatment approach has a greater occlusal treatment success rate compared to four premolar extractions [32] and presents a shorter treatment time of complete Class II malocclusions 
[28]. This may minimize root resorption and iatrogenic effects, in addition to providing greater personal and financial benefits to patients $[27,30]$.

The therapeutic choice of four second premolar extractions (Protocol 4) demonstrated a much-reduced frequency in all evaluated intervals (Table 1). Although it presents a small frequency, this protocol is usually used when anchorage can be lost, producing smaller impact on the soft tissues or in cases with moderate crowding [34,35]. Four premolar extractions frequency (Protocols 1, 2, and 4 together) decreased gradually from $65.72 \%$ (1973 to 1977) to $10.72 \%$ (2003 to 2007, Figure 1, Table 1).

The asymmetric extraction protocol of three premolars (Protocol 5 - two maxillary and one mandibular premolar) is indicated in Type 1 Class II subdivision malocclusion treatment [36]. Asymmetric extraction treatment provides an easier mechanics and better occlusal treatment success rate when compared to four premolar extractions [37] and less mandibular incisor and soft tissue retraction [38]. A variation of asymmetric extraction therapy in Class II malocclusions may include only one premolar extraction [39]. In this study, the initial frequency of indications of three premolar extractions was extremely low and increased to 7.19\% between 1998 and 2002, when it was demonstrated to provide a better occlusal success rate than four premolar extractions in Class II subdivision malocclusions [37] (Table 1). While this frequency increased and remained stable over the last two intervals, there was a drastic reduction of the frequency of indications of extractions as a whole. Thus, similar to the protocol with two maxillary premolar extractions, there was an increase in the use of this protocol.

Protocols 6, 7, and 8 exhibited low frequencies without significant differences among them (Table 1). These findings seem to demonstrate certain stability of their indications in the evaluated periods. Consequently, it is speculated that these approaches are not susceptible to influences of prevalent philosophies. Mandibular incisor extraction frequencies were observed in the literature to be around $1 \%$ [5], 2.1\% [3], 2.2\% [7], and $2.5 \%$ [6] and molar extractions, 3.0\% [3]. Mandibular incisor extraction should be considered in cases with tooth size discrepancy $[40,41]$, although it may increase overbite and overjet $[41,42]$. It is also indicated when smaller posterior teeth mesialization is needed, to shorten treatment time, to produce smaller impact on the facial profile, for Class III malocclusion treatment and in cases with some periodontal problems [42-44]. Maxillary second molar extractions can be a valuable therapeutic approach which could lead to more stable results $[45,46]$, facilitate first maxillary molar distalization, produce easier overbite correction $[41,47]$ and smaller impact on facial profile, and present a smaller percentage of extraction spaces re-openings [48].
Protocol 9 included all cases with previous dental absences. It was considered that these patients should not be excluded from the study by the fact that similar circumstances happen in daily clinical routine, and should be statistically described. They were placed in a separate group because their previous condition could have influenced the treatment planning. The total mean frequency of these cases was $11.28 \%$, and their frequencies in the several periods showed no statistically significant differences (Table 1).

Some authors suggest that a two-phase protocol in the treatment of Class II malocclusion provides best therapeutic results and greater stability $[49,50]$. However, this claim is very controversial because the influence of the orthopedic phase in the final clinical results is practically non-existent [51-55]. In this study, treatment was considered to have been conducted in two phases when patients had used only functional orthopedic appliances for more than 6 months for Class II malocclusion correction $[24,49,56,57]$. The frequency of two-phase treatment was of $6.74 \%$ and differed from other works that found a mean of 12\% [7] and 20\% [6]. Interval 6 (1998 to 2002) presented the highest frequency of two-phase treatment that was statistically different from the other periods. This greater frequency was probably due to the possible benefits that orthopedic correction could provide in Class II treatment, as was thought in the 1980s and 1990s (Table 2). On the other hand, also in Interval 6, there was a higher incidence of re-planned cases including extractions, probably due to failures or lack of patient compliance in the initial non-extraction approach [30,58] (Table 2).

\section{Clinical implications}

Studies that show frequencies of different orthodontic treatment protocols can be used as valuable parameters in the interpretation of treatment tendency with time. In this way, the orthodontist can judge these tendencies and understand the actual reasons why accepted decisions have changed over years of orthodontic practice. Finally, these findings suggest the idea that modern orthodontist should not hold on paradigms without questioning them. It is up to him to be always updated and not to rely in dogmatic treatment approaches.

\section{Conclusions}

The following conclusions are drawn from the study:

1. The non-extraction protocol frequency increased gradually from $14.29 \%$ (1973 to 1977 ) to $54.55 \%$ (2003 to 2007), with consequent reduction of extraction treatments from $85.71 \%$ (1973 to 1977) to $45.45 \%$ (2003 to 2007 ). 
2. The four premolar extraction protocol frequency decreased gradually from $65.72 \%$ (1973 to 1977 ) to 10.72\% (2003 to 2007), while the two maxillary premolar extraction protocol has shown the same frequency of indications in the same time period.

\section{Competing interests}

The authors declare that they have no competing interests.

\section{Authors' contributions}

GJ developed the idea of the investigation, supervised all the research procedures and corrected the manuscript. FRTM conducted the literature review, collected and interpreted the data and wrote his thesis. RB drafted and revised the manuscript. All authors read and approved the final manuscript.

\section{Authors' information}

GJ is Professor of the Orthodontic Department at Bauru Dental School, University of São Paulo, Brazil, and Member of the Royal College of Dentists of Canada. FRTM and RB are Graduate Students of the Orthodontic Department at Bauru Dental School, University of São Paulo, Brazil.

\section{Acknowledgements}

This paper is based on research submitted by Dr. Fábio Rogério Torres Maria in partial fulfillment of the requirements for the degree of $\mathrm{PhD}$ in Orthodontics at Bauru Dental School, University of São Paulo.

Received: 27 May 2014 Accepted: 10 July 2014

Published online: 12 August 2014

\section{References}

1. Robb SI, Sadowsky C, Schneider BJ, BeGole EA. Effectiveness and duration of orthodontic treatment in adults and adolescents. Am J Orthod Dentofacial Orthop. 1998; 114(4):383-86

2. Vig PS, Weintraub JA, Brown C, Kowalski CJ. The duration of orthodontic treatment with and without extractions: a pilot study of five selected practices. Am J Orthod Dentofacial Orthop. 1990; 97(1):45-51.

3. Weintraub JA, Vig PS, Brown C, Kowalski CJ. The prevalence of orthodontic extractions. Am J Orthod Dentofacial Orthop. 1989; 96(6):462-66.

4. Rose JS. A thousand consecutive treated orthodontic cases-a survey. Br J Orthod. 1974; 1(2):45-54.

5. Peck S, Peck H. Frequency of tooth extraction in orthodontic treatment Am J Orthod. 1979; 76(5):491-96.

6. Keim RG, Gottlieb EL, Nelson AH, Vogels DS 3rd. Study of orthodontic diagnosis and treatment procedures. Part 1. Results and trends. J Clin Orthod. 2002: 36(10):553-68.

7. Keim RG, Gottlieb EL, Nelson AH, Vogels DS 3rd. 2008 JCO study of orthodontic diagnosis and treatment procedures, part 1: results and trends. J Clin Orthod. 2008; 42(11):625-40.

8. Proffit WR. Forty-year review of extraction frequencies at a university orthodontic clinic. Angle Orthod. 1994; 64(6):407-14.

9. Zar JH. Biostatistical analysis. 3rd ed. New Jersey: Prentice Hall; 1996.

10. Grieve GW. Anatomical and clinical problems involved where extraction is indicated in orthodontic treatment. Am J Orthod Oral Surg. 1944; 30:437-43.

11. Tweed $\mathrm{CH}$. The Frankfort mandibular incisor angle (FMIA) in Orthodontic diagnosis, treatment planning and prognosis. Angle Orthod. 1954; 24 3(3):121-69.

12. Begg PR. Stone age man's dentition. Am J Orthod. 1954; 40(2):298-312 517-31.

13. Dewel BF. The clinical application of the edgewise appliance in orthodontic treatment. Am J Orthod. 1956; 42:4-28.

14. Little RM. Stability and relapse of dental arch alignment. Br J Orthod. 1990; 17(3):235-41.

15. Little RM, Wallen TR, Riedel RA. Stability and relapse of mandibular anterior alignment-first premolar extraction cases treated by traditional edgewise orthodontics. Am J Orthod. 1981; 80(4):349-65.

16. Mills JR, Vig KW. An approach to appliance therapy. Br J Orthod. 1974; 1(5):191-98
17. Mills JR, Vig KW. An approach to appliance therapy-part II. Br J Orthod. 1975; 2(1):29-36

18. Luecke PE 3rd, Johnston LE Jr. The effect of maxillary first premolar extraction and incisor retraction on mandibular position: testing the central dogma of "functional orthodontics". Am J Orthod Dentofacial Orthop. 1992; 101(1):4-12.

19. McLaughlin RP, Bennett JC. The extraction-nonextraction dilemma as it relates to TMD. Angle Orthod. 1995; 65(3):175-86.

20. Sheridan JJ. Air-rotor stripping update. J Clin Orthod. 1987; 21(11):781-88.

21. Sheridan JJ, Hastings J. Air-rotor stripping and lower incisor extraction treatment. J Clin Orthod. 1992; 26(1):18-22.

22. Frankel R. Decrowding during eruption under the screening influence of vestibular shields. Am J Orthod. 1974; 65(4):372-406.

23. Haas AJ. Palatal expansion: just the beginning of dentofacial orthopedics. Am J Orthod. 1970; 57(3):219-55.

24. Cançado RH, Pinzan A, Janson G, Henriques JF, Neves LS, Canuto CE. Occlusal outcomes and efficiency of 1- and 2-phase protocols in the treatment of Class II Division 1 malocclusion. Am J Orthod Dentofacial Orthop. 2008; 133:245-53.

25. O'Brien K, Wright J, Conboy F, Sanjie Y, Mandall N, Chadwick S, et al. Effectiveness of early orthodontic treatment with the Twin-block appliance: a multicenter, randomized, controlled trial. Part 1: Dental and skeletal effects. Am J Orthod Dentofacial Orthop. 2003; 124(3):234-43.

26. Case CS. The question of extraction in orthodontia. Amer J Orthod. 1964; 50(9):660-91.

27. Alexander RG, Sinclair PM, Goates $L J$. Differential diagnosis and treatment planning for the adult nonsurgical orthodontic patient. Am J Orthod. 1986; 89(2):95-112.

28. Janson G, Maria FR, Barros SE, Freitas MR, Henriques JF. Orthodontic treatment time in 2- and 4-premolar-extraction protocols. Am J Orthod Dentofacial Orthop. 2006; 129(5):666-71.

29. Dyer GS, Harris EF, Vaden JL. Age effects on orthodontic treatment: adolescents contrasted with adults. Am J Orthod Dentofacial Orthop. 1991; 100(6):523-30.

30. Shia GJ. Treatment overruns. J Clin Orthodont. 1986; 20(9):602-04.

31. Beckwith FR, Ackerman RJ Jr, Cobb CM, Tira DE. An evaluation of factors affecting duration of orthodontic treatment. Am J Orthod Dentofacial Orthop. 1999: 115(4):439-47.

32. Janson G, Brambilla Ada C, Henriques JF, de Freitas MR, Neves LS. Class II treatment success rate in 2- and 4-premolar extraction protocols. Am J Orthod Dentofacial Orthop. 2004; 125(4):472-79.

33. Schutz-Fransson U, Bjerklin K, Kurol J. Mandibular incisor stability after bimaxillary orthodontic treatment with premolar extraction in the upper arch. J Orofac Orthop. 1998; 59(1):47-58.

34. de Castro N. Second-premolar extraction in clinical practice. Am J Orthod. 1974; 65(2):115-37.

35. Steyn $\mathrm{CL}$, du Preez RJ, Harris AM. Differential premolar extractions. Am J Orthod Dentofacial Orthop. 1997; 112(5):480-86.

36. Janson G, de Lima KJ, Woodside DG, Metaxas A, de Freitas MR, Henriques JF. Class II subdivision malocclusion types and evaluation of their asymmetries. Am J Orthod Dentofacial Orthop. 2007: 131(1):57-66.

37. Janson G, Dainesi EA, Henriques JF, de Freitas MR, de Lima KJ. Class II subdivision treatment success rate with symmetric and asymmetric extraction protocols. Am J Orthod Dentofacial Orthop. 2003; 124(3):257-64. quiz 339.

38. Janson G, Carvalho PE, Cancado RH, de Freitas MR, Henriques JF. Cephalometric evaluation of symmetric and asymmetric extraction treatment for patients with Class II subdivision malocclusions. Am J Orthod Dentofacial Orthop. 2007; 132(1):28-35.

39. Shelley A, Beam W, Mergen J, Parks CT, Casko J. Asymmetric extraction treatment of an Angle Class II Division 2 subdivision left malocclusion with anterior and posterior crossbites. Am J Orthod Dentofacial Orthop. 2000; 118(4):462-66

40. Kokich VO Jr. Treatment of a Class I malocclusion with a carious mandibular incisor and no Bolton discrepancy. Am J Orthod Dentofacial Orthop. 2000; 118(1):107-13.

41. Reid PV. A different approach to extraction. Amer J Orthod. 1957; 43:334-65.

42. Kokich VG, Shapiro PA. Lower incisor extraction in orthodontic treatment. Four clinical reports. Angle Orthod. 1984; 54(2):139-53.

43. Faerovig E, Zachrisson BU. Effects of mandibular incisor extraction on anterior occlusion in adults with Class III malocclusion and reduced overbite. Am J Orthod Dentofacial Orthop. 1999; 115(2):113-24. 
44. Riedel RA, Little RM, Bui TD. Mandibular incisor extraction-postretention evaluation of stability and relapse. Angle Orthod. 1992; 62(2):103-16.

45. Quinn GW. Extraction of four second molars. Angle Orthod. 1985; 55(1):58-69

46. Romanides N, Servoss JM, Kleinrock S, Lohner J. Anterior and posterior dental changes in second molar extraction cases. J Clin Orthod. 1990; 24(9):559-63.

47. Basdra EK, Stellzig A, Komposch G. Extraction of maxillary second molars in the treatment of Class II malocclusion. Angle Orthod. 1996; 66(4):287-92.

48. Halderson H. Early second permanent molar extraction in orthodontics. J Can Dent Assoc. 1959; 25:549-60.

49. Bass NM. Orthopedic coordination of dentofacial development in skeletal Class II malocclusion in conjunction with edgewise therapy. Part I Am J Orthod. 1983; 84(5):361-83.

50. Dugoni SA. Comprehensive mixed dentition treatment. Am J Orthod Dentofacial Orthop. 1998; 113(1):75-84.

51. King GJ, McGorray SP, Wheeler TT, Dolce C, Taylor M. Comparison of peer assessment ratings (PAR) from 1-phase and 2-phase treatment protocols for Class II malocclusions. Am J Orthod Dentofacial Orthop. 2003; 123(5):489-96.

52. Livieratos FA, Johnston LE Jr. A comparison of one-stage and two-stage nonextraction alternatives in matched Class II samples. Am J Orthod Dentofacial Orthop. 1995; 108(2):118-31.

53. Tulloch JF, Phillips C, Proffit WR. Benefit of early Class II treatment: progress report of a two-phase randomized clinical trial. Am J Orthod Dentofacial Orthop. 1998; 113(1):62-72. quiz 3-4.

54. Tulloch JF, Proffit WR, Phillips C. Outcomes in a 2-phase randomized clinical trial of early Class II treatment. Am J Orthod Dentofacial Orthop. 2004; 125(6):657-67.

55. Von Bremen J, Pancherz H. Efficiency of early and late class II division 1 treatment. Am J Orthod Dentofacial Orthop. 2002; 121(1):31-7.

56. Basciftci FA, Uysal T, Buyukerkmen A, Sari Z. The effects of activator treatment on the craniofacial structures of Class II division 1 patients. Eur J Orthod. 2003; 25(1):87-93.

57. Cozza P, De Toffol L, lacopini L. An analysis of the corrective contribution in activator treatment. Angle Orthod. 2004; 74(6):741-48.

58. Fink DF, Smith RJ. The duration of orthodontic treatment. Am J Orthod Dentofacial Orthop. 1992; 102(1):45-51.

doi:10.1186/s40510-014-0051-z

Cite this article as: Janson et al.: Frequency evaluation of different extraction protocols in orthodontic treatment during 35 years. Progress in Orthodontics 2014 15:51.

\section{Submit your manuscript to a SpringerOpen ${ }^{\odot}$ journal and benefit from:}

- Convenient online submission

- Rigorous peer review

- Immediate publication on acceptance

- Open access: articles freely available online

- High visibility within the field

- Retaining the copyright to your article

Submit your next manuscript at $>$ springeropen.com 